\title{
Ongoing initiatives in Azerbaijan to improve the use of antibiotics; findings and implications
}

Abilova, Vafa ${ }^{1}$, Kurdi, Amanj², *Godman, Brian²,3,4

${ }^{1}$ Analytical Expertise Center, Ministry of Health, Baku, Azerbaijan Republic. Email:abilovafa@mail.ru

${ }^{2}$ Strathclyde Institute of Pharmacy and Biomedical Sciences, University of Strathclyde, Glasgow G4

ORE, United Kingdom. Email: amanj.baker@strath.ac.uk, Brian.godman@strath.ac.uk.

${ }^{3}$ Health Economics Centre, University of Liverpool Management School, Liverpool, UK. Email:

Brian.Godman@liverpool.ac.uk

4Division of Clinical Pharmacology, Karolinska Institute, Karolinska University Hospital Huddinge, SE-

141 86, Stockholm, Sweden. Email: Brian.Godman@ki.se.

${ }^{*}$ Corresponding author:

Godman, Brian

Strathclyde Institute of Pharmacy and Biomedical Sciences, University of Strathclyde, Glasgow G4

ORE, United Kingdom.

Email: Brian.godman@strath.ac.uk.

Telephone: 0141548 3825. Fax: 01415522562

Division of Clinical Pharmacology, Karolinska Institute, Karolinska University Hospital Huddinge, SE-

141 86, Stockholm, Sweden.

Email: Brian.Godman@ki.se.

Telephone + 46858581068 .

Fax + 46859581070

(Accepted for publication Expert Review of Anti-Infective Therapy - Please keep CONFIDENTIAL)

\begin{abstract}
Objectives: There have been a numerous initiatives in Azerbiajan in recent years to improve antibiotic utilization including educational programmes among patients, pharmacists and physicians. This study aimed to analyse the influence of these multiple initiatives on antibiotic utilization as a basis for suggesting future initiatives.
\end{abstract}

Methods: Observational retrospective study of total antibiotic utilization from 2011 to 2015 based on import data. The quality of aggregated antibiotic prescribing was assessed against recognised indicators including those of WHO Europe, as well as compared to neighbouring countries as reference points.

Results: There was a significant reduction in total antibiotic utilization from 17.1DIDs in 2011 in Azerbaijan to 8.02 DIDs in 2015, the lowest level compared with similar countries. Beta lactam antibiotics were typically the largest group of antibiotics with low overall use of co-amoxiclav (although relative utilisation rising), macrolides, cephalosporins and fluoroquinolones. There are concerns with rising use of tetracyclines in recent years in place of penicillins with changing pricing policies, as well as high relative use of third generation cephalosporins.

Conclusions: Multiple interventions in Azerbaijan in recent years appear to have resulted in low use of antibiotics when compared with similar countries. However, there are some concerns especially with third generation cephalosporins. There needs to be a closer look at indications to further improve antibiotic use.

Key words: antibiotic utilization; antibiotic resistance; Azerbaijan; policy initiatives; quality indicators 


\section{Introduction}

There are increasing concerns with the growing rates of antimicrobial resistance (AMR) across countries (1-3), with the resultant implications on morbidity, mortality and costs within countries. As a result, AMR has become one of the biggest public health challenges world-wide, with estimated deaths due to AMR reaching 444 million by the $2050(4,5)$, and estimated costs of $€ 9$ billion per year in Europe or higher $(1,2)$.

The occurrence and spread of AMR appears to correlate with increasing and irrational use of antibiotics (6-8). This includes the self-purchasing of antibiotics across countries, including European countries, which is typically for viral infections such as upper respiratory tract infections (URTIs) (918 ), with URTIs the predominant infection seen by physicians in ambulatory care (16).

Currently in Azerbaijan, patients need a prescription to be dispensed an antibiotic as it is illegal for pharmacists to dispense antibiotics without a prescription. However, there has been variable enforcement of this law to date. This is not helped by the fact that patients in Azerbaijan typically having to cover the full cost of antibiotics themselves, even if they are prescribed by a physician. Consequently, it does not matter to them if the cost of the medicine is the same, and may even save on physician fees as patients must typically pay to see a physician. In addition, pharmacists may make a greater profit from dispensing an antibiotic rather than a OTC medicine such as paracetamol for a temperature associated with a viral infection. This though is beginning to change with greater scrutiny over pharmacy dispensing practices with penalties for abuse (Table 1). There are though exemptions to $100 \%$ co-payment. These include patients with AIDs and HIV, where treatment is funded via the Global Fund, patients with diabetes as well as patients with tuberculosis (TB) . Having said ths, there have been many activities over the years, especially in recent years, among all key stakeholder groups to encourage rational prescribing and dispensing of antibiotics in Azerbaijan.

As a result of the various initiatives in recent years (Table 1), Azerbaijan in 2011 had the second lowest consumption of antibiotics among non-European Union (EU) southern and eastern European countries, and newly independent states, at 17.1 DIDs (DDDs per one thousand inhabitants per day), approximately half the rate seen in Turkey (8). Encouragingly, Azerbaijan had the second highest use of beta lactam antibiotics as a percentage of total of antibiotic use, with a correspondingly low use of co-amoxiclav (0.3DIDs), low use of cephalosporins, as well as low use of fluorquinolones. There was also low use of long-acting macrolides (azithromycin) in Azerbaijan versus other European countries (8).

However, it is important to see whether there is continued low, or even lower, use of antibiotics in Azerbaijan in recent years as well as continued low use of co-amoxiclav, cephalosporins and the fluorquinolones. High utilisation of co-amoxiclav increases side-effects from antibiotics, as well as resistance, resulting in co-amoxiclav typically recommended as second line after amoxicillin (19-23). There are also concerns with increasing use of cephalosporins, increasing resistance rates, rates of C. difficile, cardiac and other side-effects, as well as increasing the use and resistance to the fluoroquinolones (23-26). In addition, the WHO identified the fluoroquinolones, third- and fourthgeneration cephalosporins, macrolides and glycopeptides as being of the highest priority for risk management to improve future use (23).

There is also a need to record what reforms and initiatives have been instigated in Azerbaijan over the years to influence antibiotic utilisation. This is seen as particularly important to provide guidance to other similar countries that have higher use of antibiotics as well as concerns with high use of coamoxiclav, cephalosporins and fluoroquinolones.

We are aware that conditions such as childhood diarrhoea are an issue in Azerbaijan leading to 184 deaths per 100,000 children under five years, which is over twice the global average (27). However, targeted interventions including sanitation, nutrition, and hydration, have a greater influence on reducing mortality although antibiotics are indicated in certain situations (27-29). In addition, Azerbaijan ranks $78^{\text {th }}$ out of 188 countries in their achievement of Sustainable Development Goals, higher than Turkey, Uzbekistan, Moldova, Macedonia and Serbia (30), due to issues of childhood diseases, tuberculosis, high alcohol use, and the rise in non-communicable diseases (30), However, some of these issues are not necessarily related to antibiotic use. 
Consequently, the aim of this paper is to present and analyse total antibiotic consumption in Azerbaijan in recent years alongside ongoing initiatives to improve antibiotic use and reduce AMR. Subsequently, compare the findings with other similar European countries and former Soviet Union Republics to review potential additional measures that could be instigated in Azerbaijan if needed, as well as provide possible exemplars.

\section{Methodology}

This was a retrospective observational study of total antibiotic consumption in Azerbaijan from 2011 to 2015 based on import data. Import data on antimicrobials is provided each quarter by the wholesalers in Azerbaijan, with currently no breakdown by physician or pharmacist. Exact consumption data is currently only available for patients with HIV and TB as these medicines are provided free of charge.

Total antibiotic consumption was recorded as it is difficult to currently break these figures down into component parts within Azerbaijan. However, this is similar to surrounding European countries and former Soviet Union Republics (23).

The collection and analysis of data on drug consumption was undertaken using the ATC (Anatomical Therapeutic Chemical classification)/DDD (defined daily dose) methodology, with DDDs defined as the amount of the drug most commonly used in adults for the most common indication $(8,31,32)$. Utilisation data was further expressed in DIDs to compare utilisation rates across countries with different population sizes, similar for other diseae areas $(8,31,33,34)$.

Key measures used to examine trends over time included relative consumption measures, expressed as a percentage of total consumption as well as specific antimicrobial agents within a class (23). The quality of antibiotic prescribing was assessed using the European Surveillance of Antimicrobial Consumption (ESAC), European Centre for Disease Prevention and Control (ECDC) and WHO quality indicators $(8,23,35,36)$. These included:

- Total utilisation of antibiotics expressed as DIDs

- Utilisation of penicillins (J01C) in DIDs and as a \% of total antibiotic use

- \% utilisation of combination penicillins such as co-amoxicav as a percentage of amoxycillin use

- Total utilisation of cephalosporins ((J01D) in DIDs and as a \% vs. total antibiotics

- \% utilisation of third- and fourth-generation cephalosporins vs first and second generation cephalosporins

- Total utilisation of macrolides (J01F) in DIDs and as a \% vs. total antibiotics

- Utilisation of quinolones (J01M) expressed in DIDs as well as \% vs. total antibiotic use

We did not specifically review the utilisation of tetracylines as a quality indicator since, as mentioned, the WHO identified the fluoroquinolones, third- and fourth-generation cephalosporins, macrolides and glycopeptides as being of the highest priority for risk management to improve future use (23).

The findings in Azerbaijan were also compared to surrounding European countries and former Soviet Union Republics in 2011 and 2014 based on available data $(8,23)$, as well as European countries, especially Eastern European countries in the ECDC network in 2015 (36). These will be used to suggest additional measures within Azerbaijan to further improve the utilisation of antibiotics if pertinent acknowledging that we did not link antibiotic use to specific indications.

Since multiple initiatives and reforms were instigated over time with varying intensity, coupled with the problems with import data and their monthy fluctuations, it was impossible to undertake sophisticated statistical analyses such as time series analyses. As a result, more simple statistical tests, including trend analyses where possible, were performed to assess the level of significance, with significance seen as $p<0.05$. This is similar to other health authority analyses where multiple interventions are conducted over time with no opoortunity for time series analyses $(33,37-39)$.

No ethical approval was sought as this is a retrospective study of aggregated drug utilisation data. 


\section{Results}

There have been various ongoing initiatives and measures in Azerbaijan over the years to try and improve antibiotic utilisation. These are captured in Table 1 building on initiatives in other countries $(9$, $40,41)$.

Table 1 - Details of multiple ongoing reforms and initiatives in Azerbaijan in recent years to improve antibiotic utilisation

\begin{tabular}{|c|c|}
\hline Key stakeholders & Activities \\
\hline Physicians & $\begin{array}{l}\text { - Orchestrated government (Ministry of Health and others) initiatives in } \\
\text { April and November each year nationwide over the past years aimed at } \\
\text { physicians and other key stakeholder groups to preserve antibiotics, } \\
\text { e.g. not to over use antibiotics for viral infections. This includes a } \\
\text { variety of approaches including educational workshops with physicians, } \\
\text { leaflets, TV and other multimedia campaigns for patients and } \\
\text { pharmacists } 2 \text { to } 3 \text { times a year based on WHO approaches } \\
\text { - For physicians, this includes educational activities } 2 \text { to } 3 \text { times a year } \\
\text { to improve their knowledge of different treatment approaches } \\
\text { especially for common infections in the community during the year (in } \\
\text { addition to orchestrated activities in April and November) } \\
\text { - This also includes recommended antibiotics for infections such as } \\
\text { upper respiratory tract infections including penicillins first line. In } \\
\text { addition, advocating narrow vs. broad spectrum antibiotics where } \\
\text { pertinent. This also includes targeting ceftriaxone in recent years given } \\
\text { concerns with increasing unjustified utilisation through educational } \\
\text { workshops coupled with printed leaflets for physicians } \\
\text { - Activities in November include a week of awareness about antibiotics } \\
\text { as part of Antibiotic Awareness week. This includes multiple seminars } \\
\text { between physicians and employees of the Ministry of Health to reduce } \\
\text { inappropriate antibiotic prescribing. } \\
\text { - New clinical protocols are currently being planned in Azerbaijan with } \\
\text { increasing control over the prescribing and utilisation of antibiotics } \\
\text { - Instigation of compulsory INN prescribing similar to other countries, } \\
\text { e.g. Abu Dhabi and Lithuania[40, } 41]] \text {. The objective being to reduce } \\
\text { the marketing influence of pharmaceutical companies }\end{array}$ \\
\hline Pharmacists & $\begin{array}{l}\text { Educating pharmacists nationwide that it is illegal to sell antibiotics } \\
\text { without a prescription with inspectors regularly visiting pharmacists to } \\
\text { monitor self-purchasing levels (as this still occurs) in addition to } \\
\text { assessing the quality of medicines dispensed. This is undertaken } \\
\text { during unscheduled and planned inspections of pharmacies by Ministry } \\
\text { of Health officials to check them and educate pharmacists, i.e. in } \\
\text { addition to quality checks on the medicines dispensed, checking } \\
\text { prescription forms and monitoring the release of prescription drugs. } \\
\text { Pharmacists are also remined about pertinent legislative acts and } \\
\text { penalties for their violation to help reduce illegal selling of antibiotics } \\
\text { - Included in the general campaigns in April and November (this includes } \\
\text { antibiotic awareness week) as part of the drive to address self- } \\
\text { purchasing by educating pharmacists (and patients). This includes } \\
\text { emphasising that most infections they see are typically viral in origin so } \\
\text { do not require an antibiotic } \\
\text { It is likely that fines will start to be applied in Azerbaijan for illegal } \\
\text { selling of antibiotics without a prescription, similar to other countries in } \\
\text { the WHO Region such as the Republic of Srpska, Montenegro and } \\
\text { Turkey [9] }\end{array}$ \\
\hline Patients & $\begin{array}{l}\text { A key part of the general campaigns in April and November to try and } \\
\text { reduce requests to physicians and pharmacists for antibiotics } \\
\text { especially for suspected viral infections, which includes the majority of } \\
\text { infections seen in ambulatory care }\end{array}$ \\
\hline
\end{tabular}




\begin{tabular}{|l|l|}
\hline & $\begin{array}{l}\text { In } 2014 \text { - there was also a new pricing regulation to help reduce the } \\
\text { costs of medicines to patients. Included within this was reference } \\
\text { pricing within } 5 \text { categories. This reduced the number of manufacturers } \\
\text { as well as available choices. In addition, reducing marketing activities } \\
\text { among pharmaceutical companies } \\
\text { There are also further planned initiatives to enhance awareness of the } \\
\text { dangers of inappropriate use of antibiotics among the public to reduce } \\
\text { self purchasing of antibiotics and strengthen the message that } \\
\text { antibiotics are only available via physicians. This will include } \\
\text { multimedia campaigns }\end{array}$ \\
\hline
\end{tabular}

With respect to the new pricing regulation in 2014 (Table 1), the Tariff Council now regulates wholesale and retail prices for all registered medicines based on competition and other factors. As indicated, all registered medicines have now been divided into 5 groups depending on the manufacturing country as Azerbaijan is an import-dependent country with very limited production of medicines. After the price adjustments, wholesalers and companies cannot sell medicines at the price they wish as there are now large fines if the pharmacy (via the wholesalers) sell medicines to patients not at regulated prices. This has appreciably reduced the profitability of companies. As a result, a number of companies have left the pharmaceutical market in Azerbaijan. However, lower prices can benefit patients. This has meant some antibiotic classes have lower prices than before such as the tetracyclines.

As a result, there has been a steady decline in total antibiotic consumption in Azerbaijan in recent years, which has reached significance when total use is combined (Table 2).

Table 2 - Total consumption of J01 antibacterials by pharmacological subgroup (DIDs) in Azerbaijan

\begin{tabular}{|l|c|c|c|c|c|c|}
\hline Antibiotic & $\mathbf{2 0 1 1}$ & $\mathbf{2 0 1 2}$ & $\mathbf{2 0 1 3}$ & $\mathbf{2 0 1 4}$ & $\mathbf{2 0 1 5}$ & $\mathrm{P}$-vlaues \\
\hline Tetracyclines (J01A) & 1.4 & 2.2 & 0.8 & 0.6 & 1.81 & $\mathrm{P}=0.76$ \\
\hline Beta lactams (J01C) & 11.3 & 13.8 & 6.6 & 5.6 & 1.99 & $\mathrm{P}=0.03$ \\
\hline Cephalosporins (J01D) & 0.8 & 0.7 & 0.5 & 0.5 & 0.73 & $\mathrm{P}=0.51$ \\
\hline $\begin{array}{l}\text { Sulfonamides and trimethoprim } \\
\text { (J01E) }\end{array}$ & 0.8 & 0.3 & 0.9 & 0.5 & 0.7 & $\mathrm{P}=1$ \\
\hline $\begin{array}{l}\text { Macrolides, lincosamides and } \\
\text { streptogramins (J01F) }\end{array}$ & 1 & 1.3 & 0.9 & 0.6 & 1 & \\
\hline Quinolone antibacterials (J01M) & 0.8 & 1 & 0.7 & 0.4 & 0.84 & $\mathrm{P}=0.54$ \\
\hline Others & 1.0 & 1.2 & 1.3 & 0.3 & 0.95 & $\mathrm{P}=0.49$ \\
\hline Total & $\mathbf{1 7 . 1}$ & $\mathbf{2 0 . 5}$ & $\mathbf{1 1 . 7}$ & $\mathbf{8 . 5}$ & $\mathbf{8 . 0 2}$ & $\mathrm{P}=\mathbf{0 . 0 5}$ \\
\hline
\end{tabular}

Figure 1 provides relative consumption data in percentages compared with total antibiotic utilisation, showing increasing use of tetracyclines, macrolides, and fluoroquinolones in 2015 with lower use of beta-lactam antibiotics. Within the amoxycillins (J01C), there has been growing use of co-amoxiclav in recent years as a percentage of total amoxycillin alone or in combination (Table 3). However, absolute usage has remained at 0.2 to 0.4 DIDs over time, with the increasing percentage a factor of declining amoxycillin use (Figure 1). 
Figure 1 - Relative consumption (\%) of $\mathrm{J} 01$ antibacterials by pharmacological subgroup

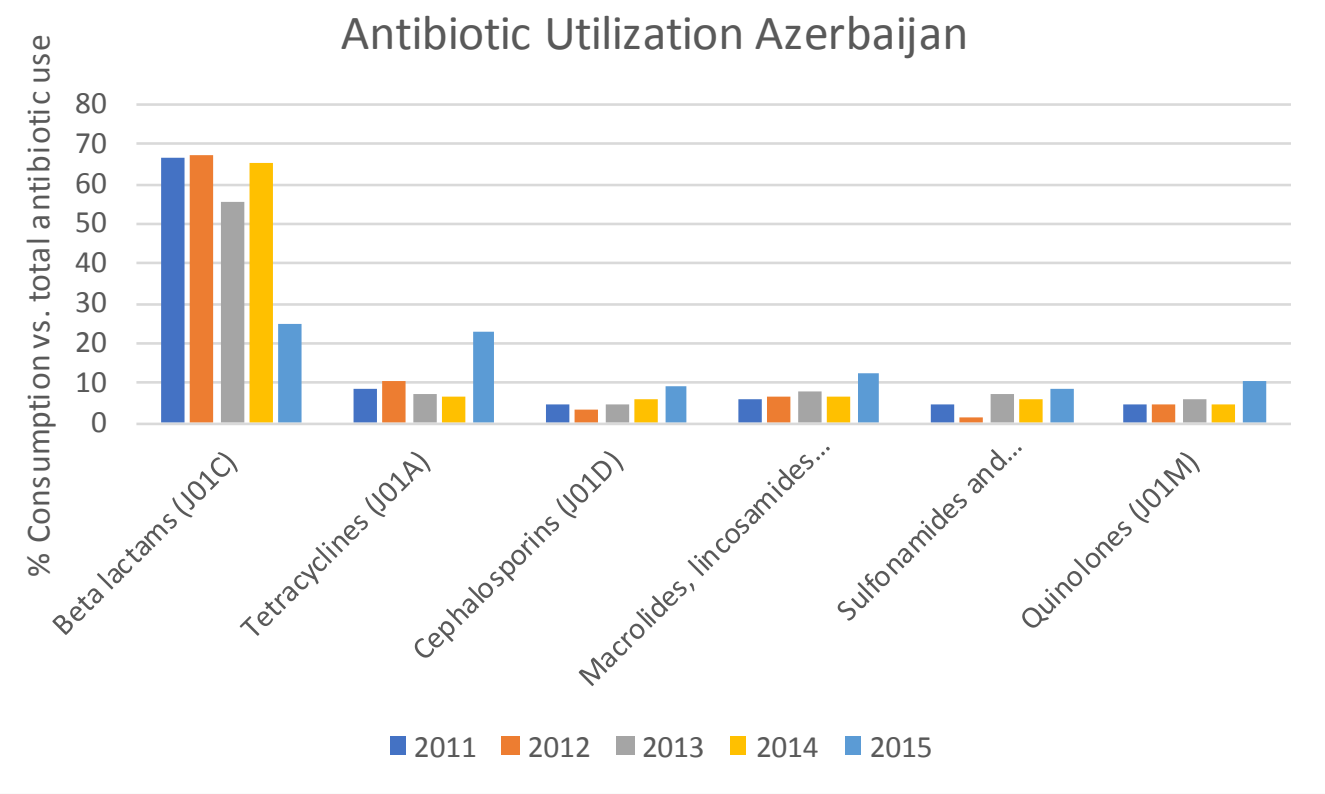

Table 3 - Relative consumption of amoxicillin, amoxicillin and clavulanic acid

\begin{tabular}{|l|c|c|c|c|c|}
\hline Antibiotic percentages and DIDs & $\mathbf{2 0 1 1}$ & $\mathbf{2 0 1 2}$ & $\mathbf{2 0 1 3}$ & $\mathbf{2 0 1 4}$ & $\mathbf{2 0 1 5}$ \\
\hline Amoxicillin (J01CA04) & $93 \%$ & $94 \%$ & $84 \%$ & $57 \%$ & $64 \%$ \\
\hline $\begin{array}{l}\text { Amoxicillin and clavulanic acid } \\
\text { (J01CR02) - DIDs and \% }\end{array}$ & $0.3-7 \%$ & $0.2-6 \%$ & $0.2-16 \%$ & $0.2-43 \%$ & $0.4-36 \%$ \\
\hline Total (DIDs) & 4.4 & 3.5 & 1.5 & 0.5 & 1.1 \\
\hline
\end{tabular}

There has been relatively low use of the cephalosporins over the study period versus other antibiotics (Figure 1); however typically this is third generation cephalosporins (Figure2). Figure 3 provides a comparison between total utilisation of antibiotics in Azerbaijan in 2014 and 2015 versus neighbouring former Soviet Union Republics and Central and Eastern European countries.

Figure 2 - Relative consumption of cephalosporins by generation (percentages of total cehalosporin use that year)

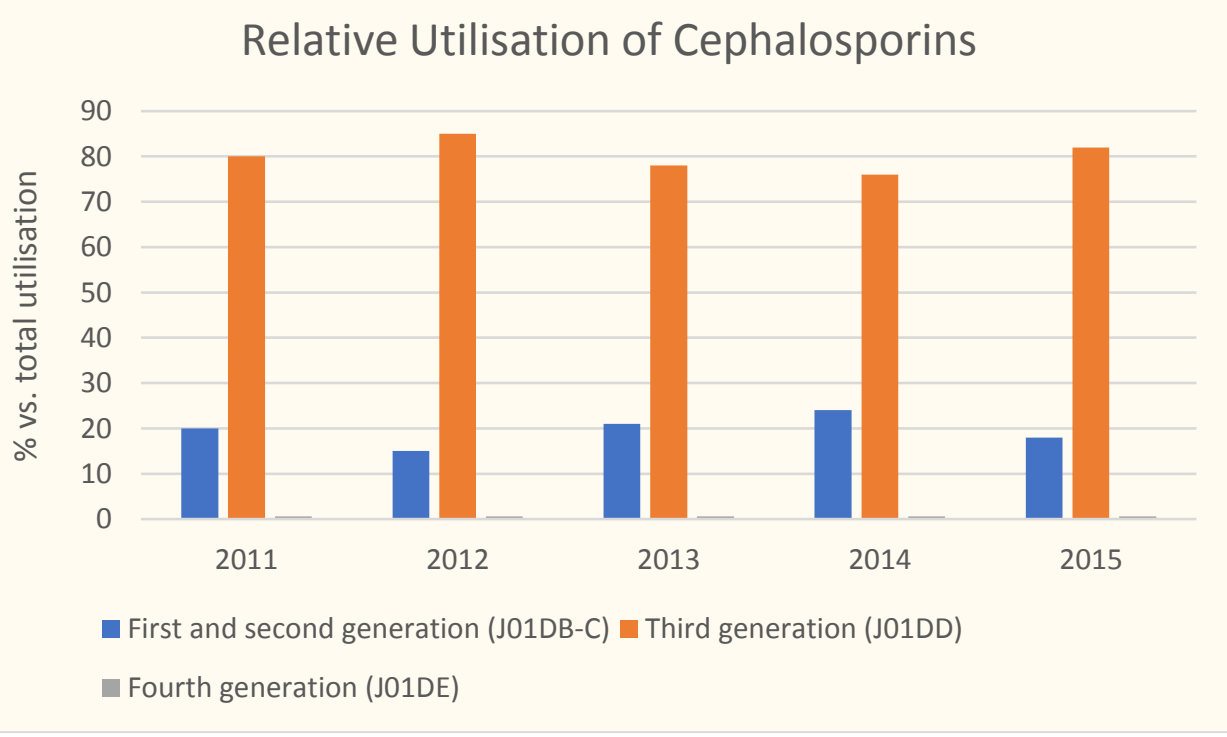


Figure 3 - Comparison of total antibiotic utilisation in Azerbaijan with selected neighbouring countries

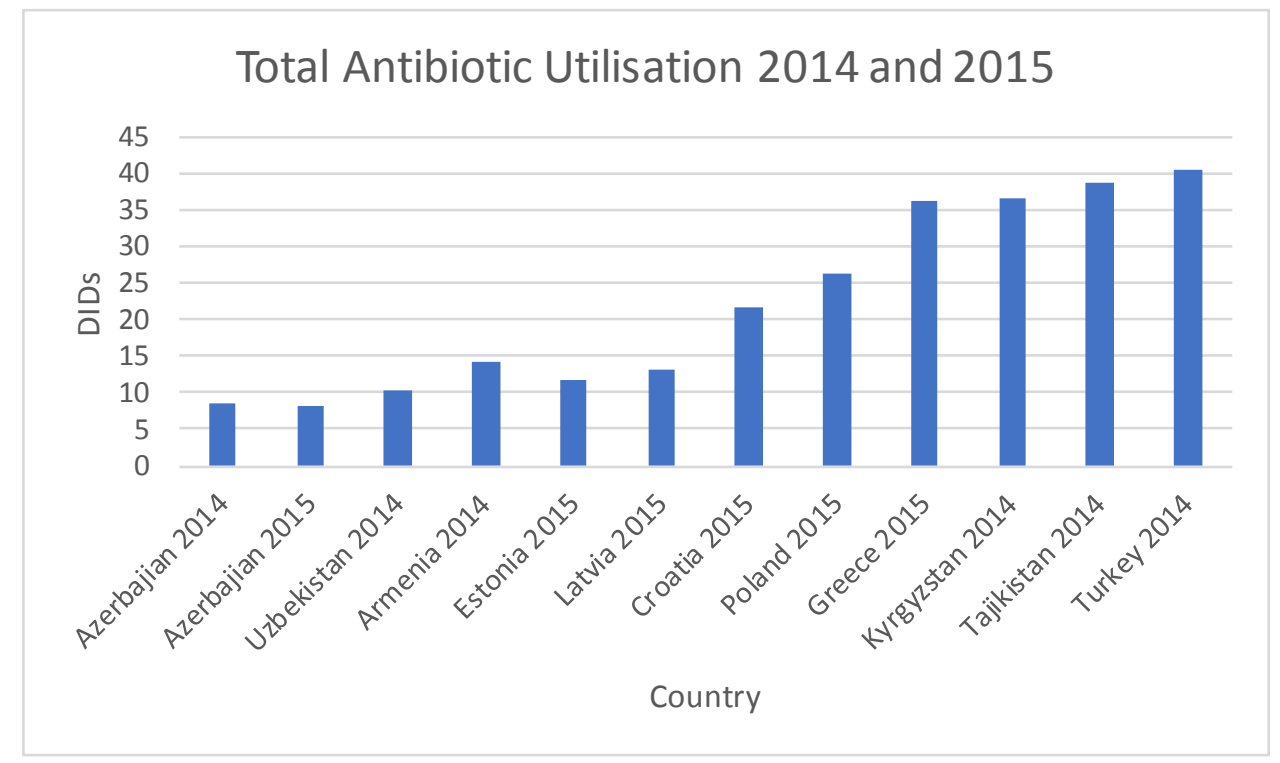

Figure 4 - Comparison of beta lactam antibiotic utilisation in Azerbaijan with selected neighbouring countries

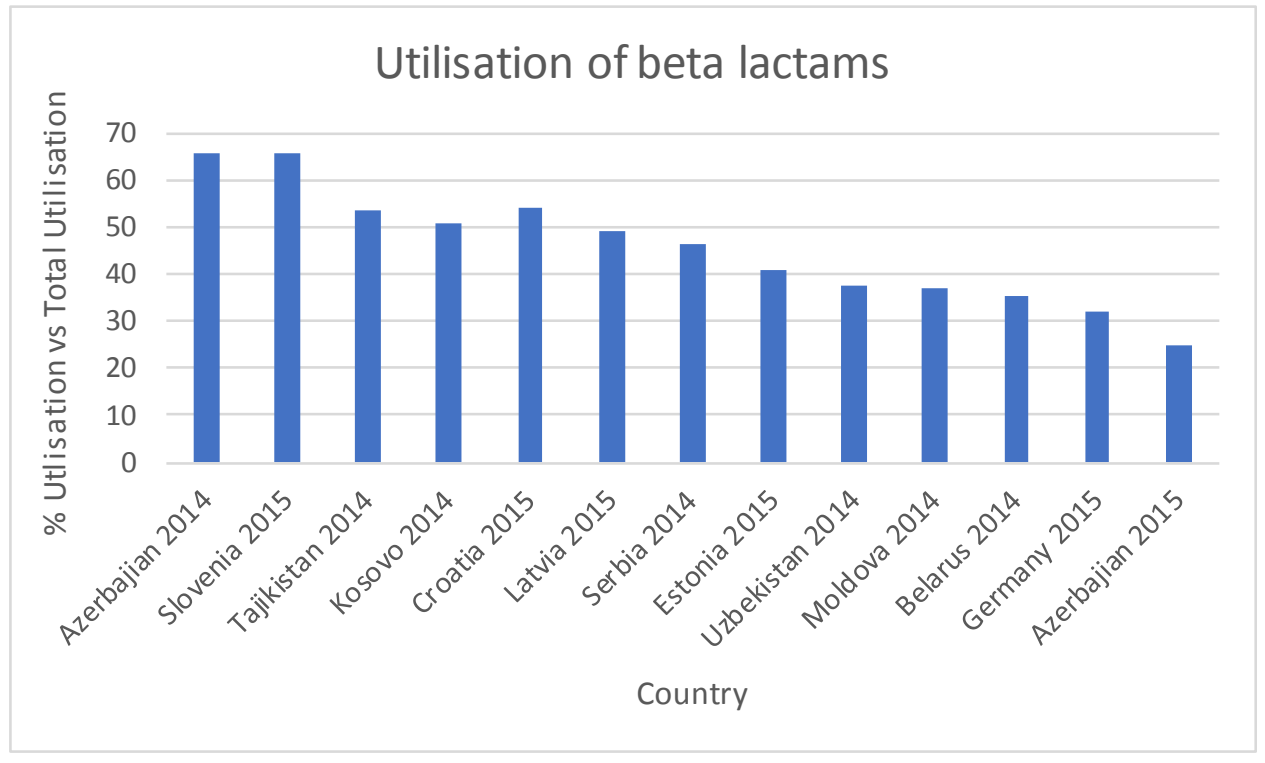

Figure 4 provides a similar comparison for beta lactam antibiotic (J01C)s, Figure 5 for macrolides (J01F) and Figure 6 for the quinolones (J01M). 
Figure 5 - Comparison of macrolide utilisation in Azerbaijan with selected neighbouring countries

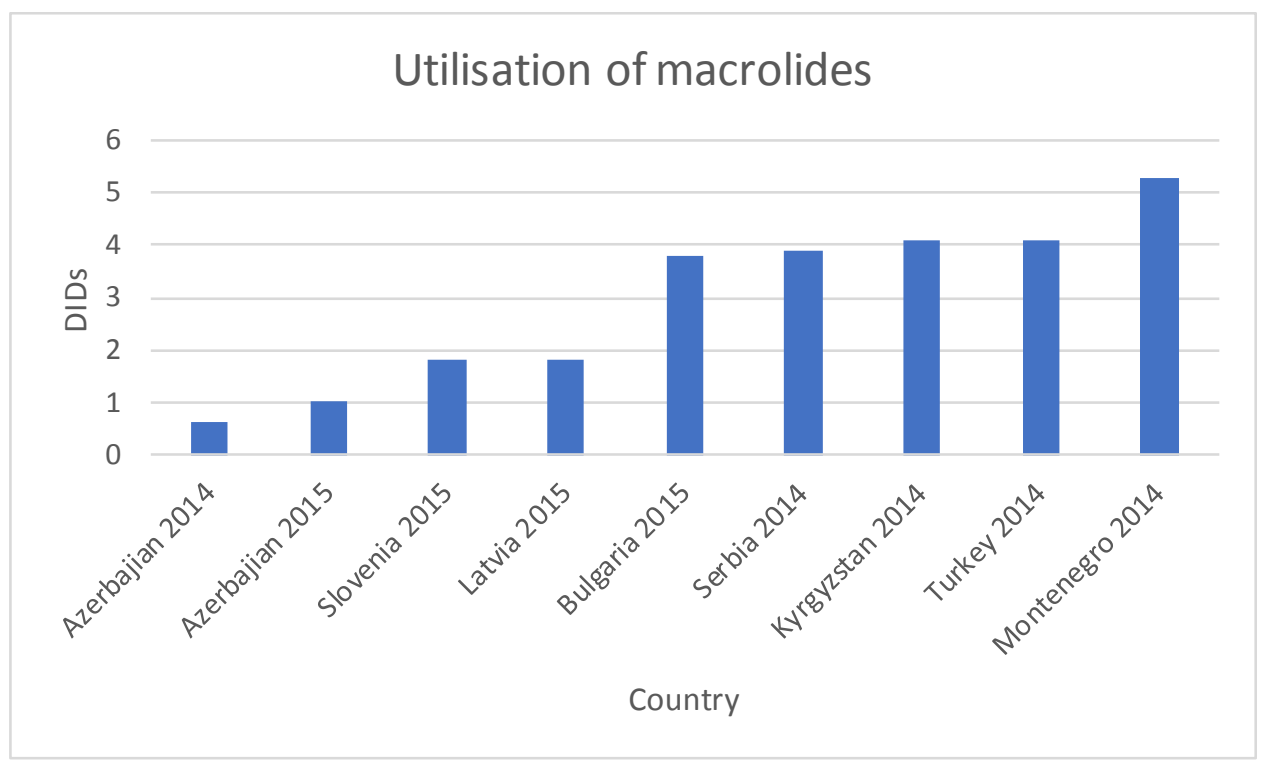

Figure 6 - Comparison of quinolone utilisation in Azerbaijan with selected neighbouring countries

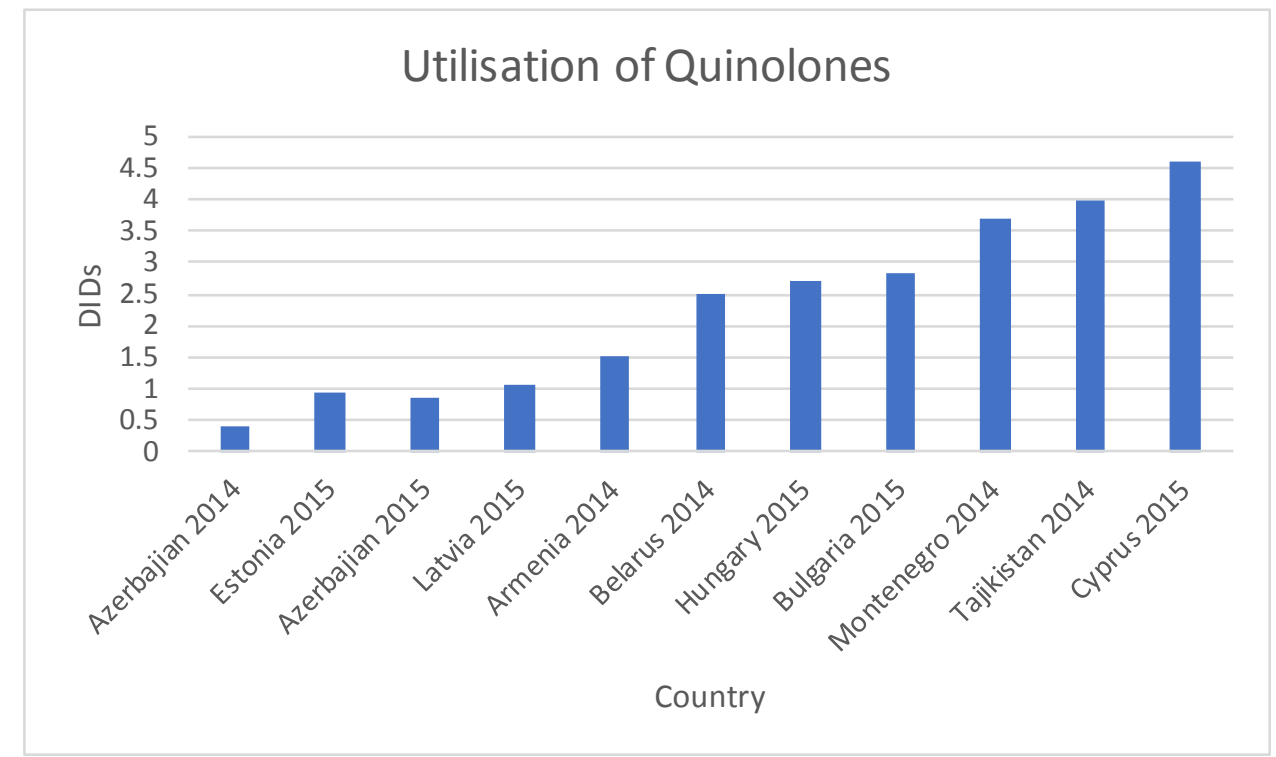

\section{Discussion}

It was encouraging to see a significant decline in the total antibiotic use in Azerbaijan in recent years (Table 2), potentiallyt helped by the ongoing multiple and intergrated initiatives in Azerbajian, targeting all key stakeholders to moderate the prescribing and dispensing of antibiotics (Table 1). This appears similar to the findings of other studies regarding anti-infectives, and other disease areas, where multiple interventions have improved the rational use of medicines $(33,34,37,38,42)$. However, we cannot say this with certainty in this research due to the limitations of available data.

Overall, there was relatively low utilisation of antibiotics within Azerbajian, which compares favourably with other European countries and former Soviet Union Republics (Figure 3)(23).(36).

The high use of beta lactam antibiotics as a percentage of total antibacterial use at $65.6 \%$ in Azerbaijan 2014 (Figure 1 was also the highest versus a number of other European countries and 
former Soviet Union Republics in 2014 (Figure 4) (23). However, there was a change in 2015, with utlilisation of penicillins decreasing as a percentage of total utilisation in Azerbaijan at $24.8 \%$ (Table 2, Figure 1). This compares with Germany but lower than Estonia, Latvia, Croatia, and Slovenia in 2015 (Figure 4) (36). This appreciable decrease in the use of penicillins, with a corresponding increase in the utilisation of tetracyclines (Tables 2, Figure 1), may well be the result of the changes in the prices of pharmaceuticals following the reforms in 2014 and a number of companies no longer marketing their products (Table 1). This will be investigated further with concerns that penicillins are not being routinely used first line in for instance for suspected bacterial URTIs, which tend to be the commonest infections in ambulatory care $(7,16)$.

There was typically low use of co-amoxiclav throughout the study period in terms of DIDs (Table 3). However, the percentage versus total amoxycillins has been rising in recent years with $43 \%$ in 2014 , which is high versus Tajikistan (2\%) and Uzbekistan (12\%), but similar to Albania (37\%) and Kyrgyzstan (49\%) and lower than Turkey (89\%) in 2014 (23). Again, this will be investigated further. However, this is likely to be more a phenomenon of reduced amoxycillin use rather than appreciably increasing co-amoxiclav use given typically low utilisation, although rising in 2015 versus 2014 (Table $3)$.

Whilst overall utilisation of the cephalosporins has remained relatively low in Azerbaijan at $6 \%$ of total antibiotic utilisation in 2014 (Figure 1) versus other former Soviet Union countries (23), there is concern with high utilisation of third generation cephalosporins in 2014 (Figure 2). This compares with only $16 \%$ in Serbia and $30 \%$ in Albania, but similar to $74 \%$ in Armenia and lower than $83 \%$ in Tajikistan in 2015 (23). Ceftriaxone is typically promoted by pharmaceutical companies as a convenient and effective cephalosporin (via personal communication), which we believe resulted in its high use among the cephalosporins over the years (Figure 2). Further educational campaigns (Table 1) are now being implemented promoted by the Ministry of Health to try and reverse this high utilisation of ceftriaxone in favour of first and second generation cephalosporins. This is alongside measures to further regulate prices of the cephalosporins to increase the use of first and second generation cephalosporins at the expense of ceftriaxone. The impact of these initiatives will be explored further in future research projects.

There was also low use of the macrolides and other J01F antibiotics in Azerbaijan in 2014 at just 0.6 DIDs (Table 2, Figure 1). This compares favourably with other former Soviet Union Republics (Figure 5) (23), as well as other Central and Eastern European countries (36). Utilisation rates will be monitored given the rise in utilisation in 2015 versus 2014 . This again may be the result in the changes in the pricing policies for antibiotics in 2014.

Encouragingly, there was also low use of fluoroquinolones in Azerbaijan at 0.4DIDs in 2014 (Table 2, Figure 1) versus other former Soviet Union Republics (Figure 6) (23), as well as other Central and Eastern European countries (36). This again may well have been helped by educational campaigns especially among physicians (Table 1 ).

The planned introduction of electronic prescribing recording the prescribing and dispensing of antibiotics in ambulatory care should help to further improve antibiotic utilisation in Azerbaijan. This will include greater scrutiny over any self-purchasing of antibiotics as well as the potential introduction of quality and other indicators to improve future use. However, any introduction of quality indicators must be based on greater knowledge of the indications for current prescribing as well as greater knowledge of resistance rates, morbidity and mortality due to infectious diseases in Azerbaijan. This especially as there has been a marginal rise in deaths due to infection and parasitic diseases in Azerbaijan in recent years, rising from 472 in 2014, to 510 in 2015 and 564 in 2016 (43). In addition, investigating further issues of affordability regarding antibiotic use, especially if this deters the purchasing of antibiotics where there are appropriate indications adversely affecting patients. These are projects for the future along with the forthcoming instigation of a National Action Plan (NAP) to combat resistance to antimicrobials and its potential impact. The NAP will include greater knowledge of current resistance rates to guide additional activities.

There also needs to be initiatives to reduce the influence of pharmaceutical companies and their marketing (Table 1), which can build on recent initiatives to enhance INN prescribing as well as further manipulate prices (Table 1).We will be monitoring these developments as well in the future. 


\section{Limitations}

We acknowledge that there are several limitations with this study. Firstly, there can be unreliability with measuring utilisation via import data. However, the relative percentages and their comparisons with other similar countries provide guidance for the future in Azerbaijan and surrounding countries. Secondly, there is no data regarding accessability, availability or affordability of antibiotics and these issues could well have also influenced antibiotic consumption. Thirdly, there were no indicators of prescribing quality in relation to any diagnoses within the available data sets, and no data currently on resistance patterns to also assess appropriateness. Lastly, we are unable to comment on any changes in mortality as a result of changing prescribing patterns. Consequently, we cannot be fully confident that the changing antibiotic patterns we have seen are beneficial or not.

However, we believe our findings are robust and already leading to changes in Azerbaijan. This will continue.

\section{Conclusion}

There are encouraging signs regarding the utilisation of antibiotics in Azerbaijan in recent years, which may wellhave been facilitated by multiple educational and other activities among key stakeholder groups. However, further research is needed befoe we can make definitive statements. In the meantime, these activities are continuing to help to improve the appropriate use of antibiotics in Azerbaijn, alongside looking more critically at diagnoses.

There are some concerns, which include the high use of ceftriaxone among the cephalosporins as well as the growing use of tetracyclines in recent years, and these will be the target of further research and activities. Monitoring the future use of antibiotics should be helped by the introduction of electronic prescribing, and the introduction of INN prescribing should help reduce the influence of pharmaceutical companies.

\section{Key Issues}

- There have been multiple and intergrated initiatives involving all key stakeholders in Azerbaijan in recent years to improve antibiotic use. These initiatives have resulted in a significant reduction in total antibiotic use

- Current utilisation of antibiotics in Azerbaijan in 2015 was 8.02 DIDs, the lowest among neigbouring countries

- There was high use of beta lactam antibiotics over the years, in line with WHO and ECDC guidance; however, growing use of tetracyclines in 2015 at the expense of the penicillins as a result of new pricing policies is a concern

- Overall low use of cephalosporins (although high use of third generation cephalosporins up to $85 \%$ of total cephalosporins), macrolides and quinolones in recent years is encouraging, especially when compared to neighbouring countries

- Future initiatives are targeting the use of third generation cephalosporins as well as any remaining self-purchasing of antibiotics. INN and electronic prescribing should help with this, as well as further improve the quality of antibiotic prescribing in Azerbaijan in the future

- The findings suggest that multiple initiatives can improve physician prescribing, in accordance with other published studies

\section{Funding}

There was no external funding for conducting this research. However, there was a small grant from the World Health Organisation (Europe) to the Karolinska Institute for the preparation of the manuscript.

\section{Declartation of interest}

B Godman received a small grant from the World Health Organisation (Europe). The authors have no other relevant affiliations or financial involvement with any organization or entity with a financial interest in or financial conflict with the subject matter or materials discussed in the manuscript apart 
from those disclosed. Peer reviewers on this manuscript have no relevant financial or other relationships to disclose.

\section{References}

Reference annotations

* Of interest

** Of considerable interest

1. Gandra S, Barter DM, Laxminarayan R. Economic burden of antibiotic resistance: how much do we really know? Clinical microbiology and infection. 2014;20(10):973-80.

${ }^{* *}$ Of considerable imprtance documenting the economic burden of AMR

2. Oxford J, Kozlov R. Antibiotic resistance--a call to arms for primary healthcare providers. International journal of clinical practice Supplement. 2013(180):1-3.

3. WHO. European strategic action plan on antibiotic resistance. Available at URL: http://www.euro.who.int/ data/assets/pdf file/0008/147734/wd14E AntibioticResistance 111380.pdf ${ }^{*}$ Discusses WHO plans to reduce AMR rates in Europe

4. ECDC. EARS-Net surveillance data. Summary of the latest data on antibiotic resistance in the European Union, November 2016. Available at URL: http://ecdc.europa.eu/en/eaad/antibiotics-getinformed/antibiotics-resistance-consumption/Documents/antibiotics-EARS-Net-summary-2016.pdf 5. Taylor J HM, Yerushalmi E, Smith R, Bellasio J, Vardavas R, et al. Estimating the economic costs of antimicrobial resistance: model and results. 2014. Available at URL:

http://www.rand.org/content/dam/rand/pubs/research reports/RR900/RR911/RAND RR911.pdf.

6. Bell BG, Schellevis F, Stobberingh E, Goossens H, Pringle M. A systematic review and metaanalysis of the effects of antibiotic consumption on antibiotic resistance. BMC Infectious Diseases. 2014;14:13-.

${ }^{* *}$ Important paper discussing the impact of overuse of antibiotics on AMR

7. $\quad$ Llor C, Bjerrum L. Antimicrobial resistance: risk associated with antibiotic overuse and initiatives to reduce the problem. Therapeutic advances in drug safety. 2014;5(6):229-41.

*Key paper exploring the association between antibiotic overuse and AMR rates

8. Versporten A, Bolokhovets G, Ghazaryan L, Abilova V, Pyshnik G, Spasojevic T, et al. Antibiotic use in eastern Europe: a cross-national database study in coordination with the WHO Regional Office for Europe. The Lancet Infectious diseases. 2014;14(5):381-7.

9. $\quad$ Markovic-Pekovic V, Grubisa N, Burger J, Bojanic L, Godman B. Initiatives to Reduce Nonprescription Sales and Dispensing of Antibiotics: Findings and Implications. J Res Pharm Pract. 2017:6(2):120-5.

10. Morgan DJ, Okeke IN, Laxminarayan R, Perencevich EN, Weisenberg S. Non-prescription antimicrobial use worldwide: a systematic review. The Lancet Infectious diseases. 2011;11(9):692701.

11. HOXHA I, Malaj A, TAKO R, MALAJ L. Survey on how antibiotics are dispensed in community pharmacies in Albania. International Journal of Pharmacy and Pharmaceutical Sciences. 2015;7(7):449-50.

${ }^{* *}$ Key paper discussing ways to improve antibiotic prescribing in ambulatory care

12. Roque F, Soares S, Breitenfeld L, López-Durán A, Figueiras A, Herdeiro MT. Attitudes of community pharmacists to antibiotic dispensing and microbial resistance: a qualitative study in Portugal. International journal of clinical pharmacy. 2013;35(3):417-24.

13. Zapata-Cachafeiro M, González-González C, Váquez-Lago JM, López-Vázquez P, LópezDurán A, Smyth E, et al. Determinants of antibiotic dispensing without a medical prescription: a crosssectional study in the north of Spain. Journal of Antimicrobial Chemotherapy. 2014;69(11):3156-60. 14. Kibuule D, Kagoya HR, Godman B. Antibiotic use in acute respiratory infections in under-fives in Uganda: findings and implications. Expert review of anti-infective therapy. 2016;14(9):863-72.

15. Kalungia AC, Burger J, Godman B, Costa JO, Simuwelu C. Non-prescription sale and dispensing of antibiotics in community pharmacies in Zambia. Expert review of anti-infective therapy. 2016;14(12):1215-23.

16. Dyar OJ, Beovic B, Vlahovic-Palcevski V, Verheij T, Pulcini C. How can we improve antibiotic prescribing in primary care? Expert review of anti-infective therapy. 2016;14(4):403-13.

${ }^{* *}$ Key paper discussing ways to improve antibiotic prescribing in ambulatory care 
17. Ocan M, Obuku EA, Bwanga F, Akena D, Richard S, Ogwal-Okeng J, et al. Household antimicrobial self-medication: a systematic review and meta-analysis of the burden, risk factors and outcomes in developing countries. BMC public health. 2015;15:742.

18. WHO. The role of pharmacist in encouraging prudent use of antibiotics and averting antimicrobial resistance: a review of policy and experience. Available at URL:

http://www.euro.who.int/ data/assets/pdf file/0006/262815/The-role-of-pharmacist-in-encouragingprudent-use-of-antibiotics-and-averting-antimicrobial-resistance-a-review-of-policy-and-experienceEng.pdf?ua $=1$

19. NHS Scotland. National Therapeutic Indicators 2014/ 2015. Available at URL: http://www.sehd.scot.nhs.uk/publications/DC20141201nti.pdf

20. Andrade RJ, Tulkens PM. Hepatic safety of antibiotics used in primary care. The Journal of antimicrobial chemotherapy. 2011;66(7):1431-46.

21. Desrosiers M, Evans GA, Keith PK, Wright ED, Kaplan A, Bouchard J, et al. Canadian clinical practice guidelines for acute and chronic rhinosinusitis. Journal of otolaryngology. 2011;40 Suppl 2:S99-193.

22. Appropriate use of amoxycillin clavulanate. BPJ 2011; 38: 28-33. Available at URL: http://www.bpac.org.nz/BPJ/2011/september/docs/bpj 38 amoxicillin pages 28-33.pdf

23. WHO. Antimicrobial Medicines Consumption (AMC) Network. 2017. Available at URL: http://www.euro.who.int/en/publications/abstracts/antimicrobial-medicines-consumption-amc-network.amc-data-20112014-2017

24. NICE. Clostridium diffificile infection: risk with broad spectrum antibiotics. Available at URL: https://www.nice.org.uk/guidance/esmpb1/resources/clostridium-difficile-infection-risk-withbroadspectrum-antibiotics-1502609568697285

25. Hancox JC, Hasnain M, Vieweg WV, Crouse EL, Baranchuk A. Azithromycin, cardiovascular risks, QTc interval prolongation, torsade de pointes, and regulatory issues: A narrative review based on the study of case reports. Therapeutic advances in infectious disease. 2013;1(5):155-65.

26. Dancer SJ. The problem with cephalosporins. The Journal of antimicrobial chemotherapy. 2001;48(4):463-78.

27. Estimates of global, regional, and national morbidity, mortality, and aetiologies of diarrhoeal diseases: a systematic analysis for the Global Burden of Disease Study 2015. The Lancet Infectious diseases. 2017;17(9):909-48.

28. Mansoor GF, Chikvaidze P, Varkey S, Higgins-Steele A, Safi N, Mubasher A, et al. Quality of child healthcare at primary healthcare facilities: a national assessment of the Integrated Management of Childhood Illnesses in Afghanistan. International journal for quality in health care. 2017;29(1):5562.

29. Edward A, Dam K, Chege J, Ghee AE, Zare H, Chhorvann C. Measuring pediatric quality of care in rural clinics-a multi-country assessment-Cambodia, Guatemala, Zambia and Kenya. International journal for quality in health care. 2016;28(5):586-93.

30. Measuring progress and projecting attainment on the basis of past trends of the health-related Sustainable Development Goals in 188 countries: an analysis from the Global Burden of Disease Study 2016. Lancet. 2017;390(10100):1423-59.

31. WHO. WHO Collaborating Centre for Drug Statistics Methodology. ATC/ DDD Index.

Available at URL: https://www.whocc.no/

32. WHO. WHO Collaborating Centre for Drug Statistics Methodology. Guidelines for ATC

Classification and DDD Assignment. 2017. Available at URL:

https://www.whocc.no/filearchive/publications/2017 guidelines web.pdf

33. Godman B, Shrank W, Andersen M, Berg C, Bishop I, Burkhardt T, et al. Policies to enhance prescribing efficiency in europe: findings and future implications. Frontiers in pharmacology.

2010;1:141.

34. Moon JC, Godman B, Petzold M, Alvarez-Madrazo S, Bennett K, Bishop I, et al. Different

initiatives across Europe to enhance losartan utilization post generics: impact and implications.

Frontiers in pharmacology. 2014;5:219.

35. Adriaenssens N, Coenen S, Versporten A, Muller A, Vankerckhoven V, Goossens H.

European Surveillance of Antimicrobial Consumption (ESAC): quality appraisal of antibiotic use in

Europe. The Journal of antimicrobial chemotherapy. 2011;66 Suppl 6:vi71-7.

${ }^{* *}$ Critical paper discussing quality indicators for antibiotic prescribing

36. ECDC. Quality indicators for antibiotic consumption in the community in Europe. Available at URL: http://ecdc.europa.eu/en/healthtopics/antimicrobial-resistance-and-consumption/antimicrobialconsumption/esac-net-database/Pages/quality-indicators-primary-care.aspx 
37. Godman B, Shrank W, Andersen M, Berg C, Bishop I, Burkhardt T, et al. Comparing policies to enhance prescribing efficiency in Europe through increasing generic utilization: changes seen and global implications. Expert review of pharmacoeconomics \& outcomes research. 2010;10(6):707-22. 38. Voncina L, Strizrep T, Godman B, Bennie M, Bishop I, Campbell S, et al. Influence of demand-side measures to enhance renin-angiotensin prescribing efficiency in Europe: implications for the future. Expert review of pharmacoeconomics \& outcomes research. 2011;11(4):469-79.

39. Bennie M, Godman B, Bishop I, Campbell S. Multiple initiatives continue to enhance the prescribing efficiency for the proton pump inhibitors and statins in Scotland. Expert review of pharmacoeconomics \& outcomes research. 2012;12(1):125-30.

40. Abuelkhair M, Abdu S, Godman B, Fahmy S, Malmstrom RE, Gustafsson LL. Imperative to consider multiple initiatives to maximize prescribing efficiency from generic availability: case history from Abu Dhabi. Expert review of pharmacoeconomics \& outcomes research. 2012;12(1):115-24.

41. Garuoliene K, Godman B, Gulbinovic J, Wettermark B, Haycox A. European countries with small populations can obtain low prices for drugs: Lithuania as a case history. Expert review of pharmacoeconomics \& outcomes research. 2011;11(3):343-9.

42. Furst J, Cizman M, Mrak J, Kos D, Campbell S, Coenen S, et al. The influence of a sustained multifaceted approach to improve antibiotic prescribing in Slovenia during the past decade: findings and implications. Expert review of anti-infective therapy. 2015;13(2):279-89.

*Important paper demonstrating the need for multiple interventions to improve antibiotic use 43. The State Statistical Committee of the Republic of Azerbaijan. Available at URL: http://www.stat.gov.az/?lang=en. 